\title{
Risk factors for postoperative delirium and subsyndromal delirium in older surgical patients in the general ward: a prospective observational study
}

\author{
Yokohama Shiritsu Daigaku \\ Mana Doi \\ Yokohama Shiritsu Daigaku \\ Kazumi Kubota \\ Yokohama Shiritsu Daigaku \\ Yuka Kanoya \\ Yokohama Shiritsu Daigaku
}

Maya Kanno ( $\sim$ mkan@yokohama-cu.ac.jp )

\section{Research article}

Keywords: Delirium, Subsyndromal delirium, General ward, Aged, Inpatients, General surgery, Acute hospital, Confusion Assessment Method

Posted Date: July 22nd, 2020

DOl: https://doi.org/10.21203/rs.3.rs-44194/v1

License: (c) (i) This work is licensed under a Creative Commons Attribution 4.0 International License. Read Full License

Version of Record: A version of this preprint was published at PLOS ONE on August 2nd, 2021. See the published version at https://doi.org/10.1371/journal.pone.0255607. 


\section{Abstract \\ Background}

Postoperative delirium (POD) among older patients is a common, serious disease and is associated with a high incidence of negative outcomes. For early detection of POD and subsyndromal delirium (SSD), this study was conducted to identify risk factors of POD and SSD in older patients in a general ward who were scheduled for surgery.

\section{Methods}

This was a prospective observational study. Study participants were older than 65 years, underwent urology surgery, and were hospitalized in the general ward between April and September 2019. Both POD and SSD were assessed by using the Confusion Assessment Method on the preoperative day, the day of surgery, and postoperative days 1-3. Personal characteristics, clinical data, cognitive function, physical functions, laboratory test results, medication use, type of surgery and anesthesia, and use of restraints were collected from medical records. Univariate and multivariate analyses were conducted to identify the risk factors for POD and SSD.

\section{Results}

A total of 101 participants (mean age 74.9 years) were enrolled; 19 (18.8\%) developed POD and SSD. The use of bed sensors (odds ratio 10.2, $p=.001$ ) and preoperative level of C-reactive protein (CRP; odds ratio $1.5, p=.054$ ) were identified as risk factors for POD and SSD.

\section{Conclusions}

POD and SSD among older patients in general wards were related to bed sensor use and the preoperative CRP level. Therefore, this study suggests that in order prevent POD and SSD for older patients in general wards, it is necessary to avoid bed sensor use as restraints and to assess the preoperative CRP level.

\section{Background}

Delirium is a common, serious disease among older patients. Older age and surgery are risk factors for delirium $[1,2]$. The incidence of postoperative delirium (POD) in the elderly population ranges from 11$51 \%$ [2], and POD in older patients is associated with many negative outcomes, including the high risk of complications, cognitive decline, prolonged hospital stay, rehospitalization, institutionalization, and mortality [2-4]. Therefore, early detection of POD among older patients and appropriate care is important to prevent the worsening of POD and the associated complications. 
We also focused on subsyndromal delirium (SSD), which is an important predictor of POD. SSD is characterized by the presence of certain symptoms of delirium without the full symptoms, and it is likely to develop into POD $[5,6]$. Furthermore, SSD in older patients is associated with many negative outcomes as well as POD, including a decline in activities of daily living (ADL), prolonged hospital stay, and high mortality [5-8]. Therefore, the identification of older patients at risk for SSD is important.

Careful observation and evaluation of the patients is necessary to prevent delirium because the symptoms of POD usually fluctuate throughout the day. Nurses are often the first to notice the symptoms of delirium because of their close involvement in the provision of patient care. However, in the general ward, nurses may face difficulties in keeping an intensive watch on all patients, especially the postoperative patients, because of a lower nurse-to-patient ratio in contrast to that in the high care units such as the intensive care unit (ICU), which provides one-to-one care. Thus, general ward nurses need to preoperatively identify patients who have high risk of POD and SSD and modify their approach to these patients. Regarding postoperative SSD, several risk factors in the ICU have been identified; these risk factors include duration of extracorporeal circulation, cardiopulmonary bypass, larger transfusion volume, etc. [9-11]. For POD, the risk factors are cognitive state [13, 14], ADL [13], and anxiety [15]. The umbrella term "functioning" that refers to all body functions, activities, and participation is an aspect of the aforementioned risk factors [12]). In contrast, only three risk factors for SSD have been identified in the general ward in previous studies: higher pain level, a recent history of falls within the past 6 months, and a longer preoperative fasting time $[16,17]$. We predicted that there are more risk factors of SSD particular to the general ward, e.g. functioning because patients in the general ward have experiences more closely resembling their usual lifestyle than the patients in the ICU, and independence of lifestyle requires higher functioning. Thus, the risk factors of SSD in older patients admitted to the general ward need to be widely investigated. In addition, we need to understand both risk factors of POD and SSD because POD and SSD are continuous concept [7]. Therefore, the aim of this study was to identify both risk factors of POD and SSD in older patients who underwent surgery and were admitted postoperatively in the general ward.

\section{Methods}

\section{Study design and participants}

This was a prospective observational study. This single-center study recruited older patients ( $>65$ years) who underwent surgery, under general or spinal anesthesia, for urological diseases and were postoperatively treated in the general ward of a tertiary care hospital in a metropolitan area of Japan between April and September 2019. Eligible patients were enrolled if they provided consent for study participation. The exclusion criteria were: (1) ICU admission, (2) low consciousness level before the surgery (Japan Coma Scale 100-300), (3) inability to speak Japanese, (4) impaired judgment because of developmental disorders or cognitive decline, and (5) preoperative onset of delirium. Participants with missing data for the dependent variables were excluded from the analysis. 
In the primary analysis of this study, we specified the key independent variables from the Comprehensive Geriatric Assessment-short version (CGA7), which comprises seven items. To calculate the sample size, the smaller incidence rates in the outcome holders and non-outcome holders require at least 6 to 10 patients per independent variable for logistic regression analysis [18]. Shim et al. [6] reported POD and SSD incident rates to be $58.1 \%$ among older patients undergoing surgery. Thus, we calculated that a minimum of 100 participants were required for the primary analysis

\section{Study procedures}

The ward nurses assessed all patients for POD and SSD for five days-the day before surgery, the day of surgery, and three consecutive days post-surgery-using the Japanese version of the Confusion Assessment Method (CAM), which was developed from the diagnostic criteria specified in the Diagnostic

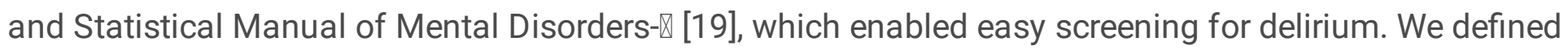
the assessment periods in this study based on prior studies [20]. On the day before surgery, the CAM was applied once during the day shift (from hospitalization until 17:00). Postoperatively, patient evaluation with the CAM was undertaken three times in a day, once during each shift (9:00 to 17:00, 17:00 to 1:00, and 1:00 to 9:00). The ward nurses received training that imparted basic knowledge on the identification of postoperative delirium and learned how to use CAM to ensure consistency in the assessments by a researcher. The training was designed to minimize the burden on the ward nurses with reference to the Short CAM Training Manual [21], as well as a previous study [22], and included: (1) the presentation, (2) a SHORT CAM POST-TEST in accordance with the instructions in the Short CAM Training Manual, and (3) an assessment for delirium in three situations, provided by a case presentation video and discussion.

\section{Measurement of study variables}

\section{Outcomes: the incidence of POD and SSD}

We specified the incidence of both POD and SSD as outcomes because episodes of SSD are closely related to POD $[5,6]$. Patients were evaluated for both POD and SSD by using the CAM, which comprises four criteria: (1) acute onset and fluctuating course, (2) inattention, (3) disorganized thinking, and (4) altered level of consciousness. The CAM algorithm for the diagnosis of delirium requires the presence of both the first and the second criteria, and of either the third or the fourth criterions [23]. In this study, POD was defined by the diagnosis of delirium based on the CAM algorithm. The SSD was defined as a presence of one or more CAM criteria and the absence of a diagnosis of delirium based on the CAM algorithm $[6,11,13,24]$. The CAM can be completed in less than 5 minutes [25], and the Japanese version of the CAM has high sensitivity $(83.3 \%)$ and high specificity $(97.6 \%)$ when validated for use by nurses compared with psychiatrists [26]. We obtained permission for the use of the Japanese version of CAM from the copyright holder (Hospital Elder Life Program) and the developer (Akira Watanabe).

\section{Demographic characteristics and surgical clinical variables}


The demographic characteristics and surgical clinical variables were defined as independent variables, and CGA7 was set as the key independent variable. We obtained age, sex, the Barthel Index, Charlson Comorbidity Index (CCl), history of dementia and cerebrovascular disease, medication use, emergency admission, visual and hearing disabilities, the Independence degree of daily living for the demented elderly, the stage of long-term care need, and the score from the CGA7 at the baseline. The use of physical restraints (belt and mitten), and bed sensors (clip and bed sensors) were examined for the day of surgery and all three days after surgery. We gathered the lesion site, operative method, anesthesia type, operative duration, intraoperative blood loss, preoperative and postoperative results of laboratory blood tests [white blood cell (WBC), red blood cell (RBC), hemoglobin $(\mathrm{Hb})$, hematocrit $(\mathrm{Ht})$, platelet (Plt), total protein (TP), albumin (Alb), blood urea nitrogen (BUN), creatinine $(\mathrm{Cr})$, sodium $(\mathrm{Na})$, potassium $(\mathrm{K})$, chlorine $(\mathrm{Cl})$, calcium (Ca), and C-reactive protein (CRP)], the use of narcotic analgesics, and the number of days that the patient's regular medication was interrupted postoperatively as surgical clinical variables that were recorded on all five days.

The $\mathrm{CCl}$ is a severity classification scoring tool for comorbidities (0 to 37); increasing score indicates worse illness [27]. The Barthel Index is an objective scale to evaluate the ADL with scores ranging from 0 to 100; increasing score indicates greater independence [28]. Both of these tools have good reliability and validity.

Independence degree of daily living for the demented elderly and the stage of long-term care need are the assessments of the appropriate care requirements of older adults and that have been developed by the Ministry of Health, Labour and Welfare of Japan. Independence degree of daily living for the demented

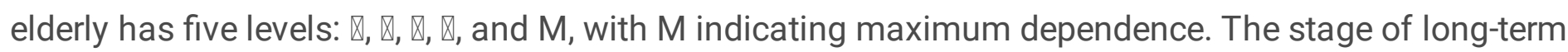
care need has seven levels: support needed ( 1 and 2 ) and care needed ( 1 to 5 ); care needed 5 indicates maximum dependence.

The CGA7 is a screening tool that extracted seven key items from a total of 40 items in four validated scales: Barthel Index, revised version of Hasegawa's Dementia Scale, Vitality Index, and Geriatric Depression Scale [29]. The CGA7 assesses functioning for older adults on aspects in the geriatric physical, psychological, and social domains. The CGA7 comprises the following questions: CGA1 (motivation): "Can the subject greet the examiner by himself/herself?", CGA2 (cognitive function): "Can the subject repeat 'cherry blossoms, cats, trains'?," CGA3 (instrumental ADL): "Can the subject go to the hospital by himself/herself?," CGA4 (cognitive function): "Can the subject recall three words in CGA2 and repeat that?," CGA5 (ADL): "Can the subject take a bath by himself/herself?," CGA6 (ADL): Can the subject use the toilet by himself/herself?," and CGA7 (emotion/mood): "Do the subject feel he/she is powerless?"). The CGA7 is assessed with "can"/"yes" or "cannot"/"no" for each question; negative outcomes on the CGA7 indicate older adults have low functioning. The specific assessment of the reliability and validity of the CGA7 test was deemed unnecessary because all four scales from which the tool was compiled have good reliability and validity.

\section{Statistical analyses}


We conducted logistic regression analysis (Forward Selection: Likelihood Ratio) with POD and SSD as the dependent variables. The primary analysis was carried out with the key independent variables in the CGA7. The secondary analysis incorporated the CGA7 and the related variables of the POD and SSD. Before the logistic regression analysis, data were analyzed by using the Student's $t$-test, Mann-Whitney $U$ test, chi-square test, and Fisher's exact test to identify the factors related to POD and SSD. Variables with a $p$-value $<0.2$ on the univariate analysis were included in the secondary analysis. All data were analyzed in SPSS statistics version 26 and the significance level was set at $p<0.05$.

\section{Results}

\section{Study population}

A total of 121 participants were recruited; of these, 20 were excluded and 101 participants were included in the final analysis (Fig. 1). The demographic characteristics and surgical clinical variables of participants are shown in Tables 1 and 2. The mean age of patients in this study population was $74.9 \pm$ 6.2 years and more than half were male $(66.3 \%)$. The mean $\mathrm{CCl}$ score was $2.3 \pm 1.1$. Most participants underwent transurethral resection (60.4\%), under general anesthesia (92.1\%), had no dementia (98.0\%), had high independence degree of daily living for the demented elderly $(97.0 \%)$, and had no long-term care need $(93.1 \%)$. The mean Barthel Index score was $97.7 \pm 9.9$. A few participants had a negative on the CGA7 (8.9\%). 
Table 1

Demographic characteristics

\begin{tabular}{|c|c|c|c|c|}
\hline \multirow[b]{2}{*}{ Variables } & \multirow{2}{*}{$\begin{array}{l}\text { Total, } n \\
=101\end{array}$} & \multicolumn{3}{|c|}{ CAM delirium status } \\
\hline & & $\begin{array}{l}\text { No } \\
\text { delirium, } \mathrm{n} \\
=82\end{array}$ & $\begin{array}{l}\text { POD and } \\
\text { SSD, } \mathrm{n}=19\end{array}$ & $p$-value \\
\hline Age (years) ${ }^{\mathrm{a}}$, mean (SD) & $\begin{array}{l}74.9 \\
(6.2)\end{array}$ & $74.8(6.9)$ & $75.7(6.9)$ & 0.623 \\
\hline $\operatorname{Men}^{b}, \mathrm{n}(\%)$ & $\begin{array}{l}67 \\
(66.3)\end{array}$ & $51(62.2)$ & $16(84.2)$ & 0.439 \\
\hline Barthel Index ${ }^{a}$, mean (SD) & $\begin{array}{l}97.7 \\
(9.9)\end{array}$ & $98.1(9.1)$ & $94.4(16.0)$ & 0.329 \\
\hline $\mathrm{CCl}^{\mathrm{a}}$, mean (SD) & $\begin{array}{l}2.3 \\
(1.1)\end{array}$ & $2.2(1.1)$ & $2.8(1.4)$ & $0.023^{\star}$ \\
\hline Dementia $^{\mathrm{b}}, \mathrm{n}(\%)$ & $2(2.0)$ & $0(0)$ & $2(10.5)$ & $0.034^{\star}$ \\
\hline Cerebrovascular disease $^{\mathrm{b}}, \mathrm{n}(\%)$ & $6(5.9)$ & $4(4.9)$ & $2(10.5)$ & 0.315 \\
\hline Emergency admission ${ }^{\mathrm{b}}, \mathrm{n}(\%)$ & $2(2.0)$ & $0(0)$ & $2(10.5)$ & $0.034^{\star}$ \\
\hline Number of medications ${ }^{a}$, mean (SD) & $\begin{array}{l}4.1 \\
(4.0)\end{array}$ & $3.7(4.5)$ & $5.8(30.5)$ & $0.016^{\star *}$ \\
\hline Anticholinergic drug use ${ }^{\mathrm{b}}, \mathrm{n}(\%)$ & $5(5.0)$ & $3(3.7)$ & $2(10.5)$ & 0.236 \\
\hline $\begin{array}{l}\text { Diazepam conversion (regular drugs) }{ }^{\mathrm{a}} \text {, mean } \\
\text { (SD) }\end{array}$ & $\begin{array}{l}0.8 \\
(2.2)\end{array}$ & $0.7(2.0)$ & $1.2(3.2)$ & 0.520 \\
\hline Non-visual disorder ${ }^{\mathrm{b}}, \mathrm{n}(\%)$ & $\begin{array}{l}16 \\
(15.8)\end{array}$ & $12(14.6)$ & $4(21.1)$ & 0.495 \\
\hline Non-hearing disorder, n (\%) & $\begin{array}{l}71 \\
(70.3)\end{array}$ & $59(72.0)$ & $12(63.2)$ & 0.655 \\
\hline \multicolumn{5}{|l|}{$\begin{array}{l}\text { Degree of Independence degree of daily living } \\
\text { for the demented elderly }{ }^{\mathrm{b}}, \mathrm{n}(\%)\end{array}$} \\
\hline Independent & $\begin{array}{l}98 \\
(97.0)\end{array}$ & $82(100.0)$ & $16(84.2)$ & \\
\hline \multicolumn{5}{|c|}{$\begin{array}{l}\text { Note. SD, standard deviation; CCl, Charlson Comorbidity Index; CGA7, Comprehensive Geriatric } \\
\text { Assessment-short version. }\end{array}$} \\
\hline \multicolumn{5}{|c|}{ Continuous variables were analyzed by the Student's $t$-test or ${ }^{\mathrm{a}}$ Mann-Whitney Utest. } \\
\hline \multicolumn{5}{|c|}{ Categorical variables were analyzed by the chi-square test or ${ }^{b}$ Fisher's exact test. } \\
\hline$P$-values significant at the $20 \%$ and $5 \%$ levels & own as & $<0.2$ and & $=0.05$ & \\
\hline
\end{tabular}




\begin{tabular}{|c|c|c|c|c|}
\hline & Total, $\mathbf{n}$ & CAM delir & status & \\
\hline ( & $1(1.0)$ & $0(0)$ & $1(5.3)$ & \\
\hline$\square$ & $2(2.0)$ & $0(0)$ & $2(10.5)$ & $0.006^{* *}$ \\
\hline Stage of long-term care need ${ }^{\mathrm{b}}, \mathrm{n}(\%)$ & & & & \\
\hline Independent & $\begin{array}{l}94 \\
(93.1)\end{array}$ & $76(92.7)$ & $18(94.7)$ & \\
\hline Needed support 1 & $3(3.0)$ & $2(2.4)$ & $1(5.3)$ & \\
\hline Needed support 2 & $1(1.0)$ & $1(1.2)$ & $0(0)$ & \\
\hline Requiring care 5 & $1(1.0)$ & $1(1.2)$ & $0(0)$ & 0.779 \\
\hline Negative outcome in CGA7, n (\%) & $9(8.9)$ & $6(7.3)$ & $3(15.8)$ & 0.36 \\
\hline $\begin{array}{l}\text { (1) Can the subject greet the examiner by } \\
\text { himself/herself? }\end{array}$ & $1(1.0)$ & $1(1.2)$ & $0(0)$ & 1.00 \\
\hline $\begin{array}{l}\text { (2) Can the subject repeat 'cherry blossoms, } \\
\text { cats, trains'? }\end{array}$ & $1(1.0)$ & $1(1.2)$ & $0(0)$ & 1.00 \\
\hline $\begin{array}{l}\text { (3) Can the subject go to the hospital by } \\
\text { himself/herself? }\end{array}$ & $5(5.0)$ & $3(3.7)$ & $2(10.5)$ & 0.24 \\
\hline $\begin{array}{l}\text { (4) Can the subject recall three words in CGA2 } \\
\text { and talk that? }\end{array}$ & $1(1.0)$ & $1(1.2)$ & $0(0)$ & 1.00 \\
\hline $\begin{array}{l}\text { (5) Can the subject take a bath by } \\
\text { himself/herself? }\end{array}$ & $5(5.0)$ & $3(3.7)$ & $2(10.5)$ & 0.24 \\
\hline $\begin{array}{l}\text { (6) Can the subject use the toilet by } \\
\text { himself/herself? }\end{array}$ & $1(1.0)$ & $0(0)$ & $1(5.3)$ & 0.19 \\
\hline (7) Do the subject feel he/she is powerless? & $3(3.0)$ & $2(2.4)$ & $1(5.3)$ & 0.47 \\
\hline Use of physical restraint ${ }^{b}$ & $2(2.0)$ & $0(0)$ & $2(10.5)$ & $0.034 \star \star$ \\
\hline Bed sensor use ${ }^{b}$ & $\begin{array}{l}12 \\
(11.9)\end{array}$ & $5(6.1)$ & $7(36.8)$ & $0.001^{* *}$ \\
\hline $\begin{array}{l}\text { Note. SD, standard deviation; } \mathrm{CCl} \text {, Charlson Co } \\
\text { Assessment-short version. }\end{array}$ & dity Ind & CGA7, Cc & ensive $C$ & \\
\hline Continuous variables were analyzed by the Stc & s $t$-test o & Mann-Wh & Utest. & \\
\hline Categorical variables were analyzed by the chi & re test o & Fisher's exa & & \\
\hline$P$-values significant at the $20 \%$ and $5 \%$ levels & wh as & 0.2 an & 0.05 . & \\
\hline
\end{tabular}


Table 2

Surgical clinical variables

\section{Total, $\mathrm{n}=\quad$ CAM delirium status \\ 101}

Variables

Lesion site ${ }^{\mathrm{b}}, \mathrm{n}(\%)$

Kidney tumor

Ureteral cancer

Bladder cancer

Prostatic cancer

Benign prostatic hypertrophy

Testicular tumor

Penile cancer

Others

Operative methods ${ }^{\mathrm{b}}, \mathrm{n}(\%)$

Laparoscopic surgery

Transurethral resection

Others

Anesthesia $^{\mathrm{b}}, \mathrm{n}(\%)$

General anesthesia

Spinal anesthesia

$10(9.9) \quad 8(9.8) \quad 2(10.5)$

$2(2.0) \quad 2(2.4) \quad 0(0)$

$50(49.5) \quad 42(51.2) \quad 8(42.1)$

$16(15.8) \quad 12(14.6) \quad 4(21.1)$

$13(12.9) \quad 9(11.0) \quad 4(21.1)$

$2(2.0) \quad 1(1.2) \quad 1(5.3)$

$3(3.0)$

$3(3.7)$

$0(0)$

$5(5.0)$

$5(6.1)$

$0(0)$

0.621

$29(28.7) \quad 24(29.3) \quad 5(26.3)$

$61(60.4) \quad 50(61.0) \quad 11(57.9)$

$11(10.9) \quad 8(9.8) \quad 3(15.8)$

0.668

$93(92.1) \quad 74(90.2) \quad 19(100.0)$

$8(7.9) \quad 8(9.8) \quad 0(0)$

0.346

Results of preoperative blood tests, mean (SD)

$\operatorname{WBC}\left(10^{3} / \mu \mathrm{L}\right)^{\mathrm{a}}$

$6.1(1.6)$

$7.1(2.5)$

0.141 *

$\operatorname{RBC}\left(10^{6} / \mu \mathrm{L}\right)$

$4.3(0.5) \quad 4.3(0.5)$

$4.3(0.5)$

0.684

Note. SD, standard deviation.

Continuous variables were analyzed by the Student's $t$-test or ${ }^{\mathrm{a}}$ Mann-Whitney $U$ test.

Categorical variables were analyzed by the chi-square test or bisher's exact test.

$P$-values significant at the $20 \%$ and $5 \%$ levels are shown as *, $p<0.2$ and $* *, p<0.05$. 


\begin{tabular}{|c|c|c|c|c|}
\hline \multirow[b]{2}{*}{$\mathrm{Hb}(\mathrm{g} / \mathrm{dL})^{\mathrm{a}}$} & \multirow{2}{*}{$\begin{array}{l}\text { Total, } \mathrm{n}= \\
101\end{array}$} & \multicolumn{3}{|c|}{ CAM delirium status } \\
\hline & & $13.4(1.8)$ & $13.0(2.1)$ & 0.546 \\
\hline $\mathrm{Ht}(\%)$ & $40.1(5.2)$ & $40.2(6.0)$ & $39.2(5.8)$ & 0.501 \\
\hline Plt $\left(10^{3} / \mu \mathrm{L}\right)^{\mathrm{a}}$ & $\begin{array}{l}237.5 \\
(83.2)\end{array}$ & $234.7(76.9)$ & $252.6(106.8)$ & 0.798 \\
\hline $\operatorname{TP}(\mathrm{g} / \mathrm{dL}), \mathrm{n}=100^{\mathrm{a}}$ & $7.2(0.6)$ & $7.2(0.7)$ & $7.1(0.5)$ & 0.615 \\
\hline Alb $(\mathrm{g} / \mathrm{dL}), \mathrm{n}=100^{\mathrm{a}}$ & $4.1(0.4)$ & $4.1(0.4)$ & $4.1(0.6)$ & 0.751 \\
\hline $\operatorname{BUN}(\mathrm{mg} / \mathrm{dL})^{\mathrm{a}}$ & $18.8(6.8)$ & $18.1(5.6)$ & $21.6(10.1)$ & 0.314 \\
\hline $\mathrm{Cr}(\mathrm{mg} / \mathrm{dL})^{\mathrm{a}}$ & $1.0(0.6)$ & $1.0(0.6)$ & $1.2(0.6)$ & 0.279 \\
\hline $\mathrm{Na}(\mathrm{mmol} / \mathrm{L})^{\mathrm{a}}$ & $\begin{array}{l}141.5 \\
(2.4)\end{array}$ & $141.8(2.2)$ & $140.3(2.8)$ & $0.056^{\star}$ \\
\hline $\mathrm{K}(\mathrm{mmol} / \mathrm{L})^{\mathrm{a}}$ & $4.3(0.4)$ & $4.3(0.4)$ & $4.4(0.4)$ & 0.426 \\
\hline $\mathrm{Cl}(\mathrm{mmol} / \mathrm{L})$ & $\begin{array}{l}104.6 \\
(2.5)\end{array}$ & $104.8(2.5)$ & $103.6(2.6)$ & $0.058^{\star}$ \\
\hline $\mathrm{Ca}(\mathrm{mmol} / \mathrm{L})$ & $9.4(0.4)$ & $9.4(0.4)$ & $9.5(0.5)$ & 0.305 \\
\hline $\mathrm{CRP}(\mathrm{mg} / \mathrm{L})^{\mathrm{a}}$ & $0.5(1.9)$ & $0.3(0.5)$ & $1.8(4.0)$ & 0.030 ** \\
\hline Operative duration (min) ${ }^{a}$, mean (SD) & $\begin{array}{l}119.7 \\
(112.4)\end{array}$ & $\begin{array}{l}116.0 \\
(113.7)\end{array}$ & $141.1(113.7)$ & $0.088^{*}$ \\
\hline $\begin{array}{l}\text { Intraoperative blood loss }(\mathrm{mL})^{\mathrm{a}} \text {, mean } \\
\text { (SD) }\end{array}$ & $\begin{array}{l}87.9 \\
(87.0)\end{array}$ & $95.0(234.0)$ & $55.3(146.1)$ & 0.847 \\
\hline Use of narcotic analgesics, n (\%) & $28(27.7)$ & $22(26.8)$ & $6(31.6)$ & 0.777 \\
\hline \multicolumn{5}{|l|}{ Postoperative physical status, n (\%) } \\
\hline Inflammation ${ }^{b}$ & $2(2.0)$ & $1(1.2)$ & $1(5.3)$ & 0.342 \\
\hline Anemia & $27(26.7)$ & $20(24.4)$ & $7(36.8)$ & 0.269 \\
\hline Undernutrition & $28(27.7)$ & $21(25.6)$ & $7(36.8)$ & 0.395 \\
\hline
\end{tabular}

Note. SD, standard deviation.

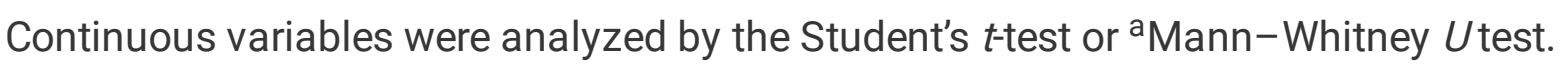

Categorical variables were analyzed by the chi-square test or ${ }^{\mathrm{b}}$ Fisher's exact test.

$P$-values significant at the $20 \%$ and $5 \%$ levels are shown as *, $p<0.2$ and $* *, p<0.05$. 


\begin{tabular}{|c|c|c|c|c|}
\hline \multirow[b]{2}{*}{ Electrolyte abnormality ${ }^{b}$} & \multirow{2}{*}{$\begin{array}{l}\text { Total, } \mathrm{n}= \\
101\end{array}$} & \multicolumn{3}{|c|}{ CAM delirium status } \\
\hline & & $11(13.4)$ & $0(0)$ & $0.119 *$ \\
\hline Decline in renal function ${ }^{b}$ & $18(17.8)$ & $13(15.9)$ & $5(26.3)$ & 0.322 \\
\hline $\begin{array}{l}\text { Duration of suspension of regular } \\
\text { medication }^{\mathrm{a}} \text {, mean (SD) }\end{array}$ & $1(0.9)$ & $1.1(0.9)$ & $0.9(4.7)$ & 0.541 \\
\hline Postoperative use of sleeping pills ${ }^{b}, n(\%)$ & $8(7.9)$ & $6(7.3)$ & $2(10.5)$ & 0.643 \\
\hline \multicolumn{5}{|l|}{ Note. SD, standard deviation. } \\
\hline \multicolumn{5}{|c|}{ Continuous variables were analyzed by the Student's $t$-test or a Mann-Whitney Utest. } \\
\hline \multicolumn{5}{|c|}{ Categorical variables were analyzed by the chi-square test or ${ }^{\mathrm{b}}$ Fisher's exact test. } \\
\hline$P$-values significant at the $20 \%$ and $5 \%$ lev & are show & $* *, p<0.2$ & $p<0.05$ & \\
\hline
\end{tabular}

\section{[Insert Fig. 1 here]}

Figure 1. Patient enrollment flowchart

[Insert Table 1 here]

[Insert Table 2 here]

\section{Association between indicators and POD and SSD by univariate analysis}

A total of 19 participants were postoperatively observed for POD and SSD by CAM (POD, $n=3 ; S S D, n=$ $16)$. Both $P O D$ and SSD were significantly associated with low independence degree of daily living for the demented elderly $(p=0.006)$, many medications $(p=0.016)$, preoperative high $\operatorname{CRP}(p=0.030)$, restraint use $(p=0.034)$, and bed sensor use $(p=0.001)$ on univariate analysis (Tables 1 and 2$)$.

\section{Risk factors of POD and SSD by logistic regression analysis}

First, we conducted a primary analysis by the logistic regression analysis, which included the key independent variables. The model did not work out due to the separation variables, which is an issue in the logistic regression analysis [30].

Second, we included the CGA7 as a key independent variable along with eight independent variables for the logistic regression analysis (e.g., $\mathrm{CCl}$, medication use, preoperative $\mathrm{WBC}$, preoperative $\mathrm{Na}$, preoperative $\mathrm{Cl}$, preoperative CRP, operative duration, and bed sensor use), which showed correlations on univariate analysis ( $p$-value $<0.2$ ). Logistic regression analysis showed that POD and SSD were associated with bed sensor use [odds ratio (OR) 10.2; $p=0.001,95 \%$ confidence interval $(\mathrm{Cl}) 2.68-38.65$ ] and preoperative high CRP (OR 1.5; $p=0.054,95 \% \mathrm{Cl} 0.99-2.19$; Table 3 ). 
Table 3

Risk factors of POD and SSD on logistic regression analysis

\begin{tabular}{|llllll|}
\hline Variables & $\boldsymbol{\beta}$ & SE & $\boldsymbol{p}$-value & OR & $95 \% \mathrm{Cl}$ \\
\hline $\begin{array}{l}\text { Bed sensor use } \\
\text { (No, 0; Yes, 1) }\end{array}$ & 2.321 & 0.681 & 0.001 & 10.18 & $2.682-38.652$ \\
\hline Preoperative CRP (mg/dL) & 0.388 & 0.202 & 0.054 & 1.47 & $0.993-2.188$ \\
\hline Note. $\beta$, regression coefficient; SE, standard error; 95\% Cl, 95\% confidence interval \\
\hline
\end{tabular}

\section{Discussion}

In this study, the incidence of POD and SSD was $18.8 \%$, compared to the $58.1-67.9 \%$ that was reported previously $[6,16,17]$. Moreover, the incidence was low in comparison to ranges from $11-51 \%$ as the common incidence of POD in older patients [2]. Three reasons may account for this difference. The first reason would be the characteristics of the department for patient treatment. Participants of prior studies underwent joint replacement surgery $[16,17]$. Patients with joint disorders tend to have joint pain and limited mobility, that may limit the preoperative ADL, which is a risk factor for SSD [13, 31]. However, participants in this study had a greater independence of ADL. Moreover, we predict that transurethral resection, which is a minimally invasive surgery, constituted $60.4 \%$ of the surgeries in this study and may have affected the low incidence of POD and SSD. Thus, high ADL and minimally invasive surgery caused a lower incidence of POD and SSD. The second reason would be the selection bias of the surgical patients. Primary doctors might select healthy older patients to conduct a safe surgery. In addition, participants had few negatives on the CGA7, which is an indicator of the independence of functioning, and most participants of this study might be independent. Prior studies have found that the CGA is associated with POD for older patients [32,33]. Thus, while we predicted that high functioning for older patients may have reduced the incidence of POD and SSD, we did not find an associated correlation. The third reason would be the influence of good nursing care. Pain management, maintenance of nutrition and hydration, promotion of mobilization and sleep are effective for preventing delirium [34]. Thus, we predicted that good nursing care, comprising the abovementioned factors, had been performed and might have prevented the development of POD and SSD.

Furthermore, the logistic regression analysis suggested that bed sensor use was associated with an increased risk of POD and SSD. We attributed two reasons for this. The first reason is the intentional bed sensor use by nurses. Bed sensors are usually used to prevent falls. We predicted that nurses expected signs of POD and SSD and intentionally used the bed sensor to check mobility in older patients. The second reason is the restraint of using a bed sensor. Using a bed sensor makes older patients unable to move freely because of its high monitoring function. The World Health Organization found that physical restraint, defined as something that restricts a person's ability to move freely [35] was a risk factor of POD [36]. Therefore, using bed sensors might increase the risk for POD and SSD. It is necessary to avoid using bed sensors as restraint to prevent the incidence of POD and SSD. 
Next, the secondary analysis suggested that a preoperative high CRP level is associated with an increased risk of POD and SSD, which has also been suggested previously [37, 38]. Ward nurses can check the CRP of patients in the general ward because CRP is routinely tested before surgery. Thus, preoperative CRP is a possible biomarker of risk for POD and SSD in older patients in the general ward.

This study has several limitations. First, there was a low incidence of POD and SSD in contrast to the expectation because most of the participants were independent and healthy. This independence limited factors that have a strong risk relationship and may have been a cause of missing other potential factors. Second, the influence of nursing care could not be evaluated. Good nursing care might suppress the relationship between other factors and the study outcomes. Third, we did not assess postoperative cognitive functions such as dementia. There was a possibility to identify participants with dementia as POD and SSD because of their similarity. However, despite these limitations, this study provides a knowledge base for the evaluation of POD and SSD in older patients in the general ward in future studies. Further large-scale studies are needed to confirm the findings of these factors.

In conclusion, POD and SSD among older patients in the general ward are related to bed sensor use and the preoperative CRP level. Therefore, this study suggests that to prevent POD and SSD among older patients in the general wards, it is necessary to avoid bed sensor use as restraint and assess the preoperative CRP level.

\section{Abbreviations}

$A D L$, activities of daily living; $P O D$, postoperative delirium; SSD, subsyndromal delirium; $C A M$, Confusion Assessment Method; OR, odds ratio, $\mathrm{Cl}$, confidence interval; $\mathrm{WBC}$, white blood cell; $\mathrm{RBC}$, red blood cell; $\mathrm{Hb}$, hemoglobin; $\mathrm{Ht}$, hematocrit; Plt, platelet; TP, total protein; Alb, albumin; BUN, blood urea nitrogen; $\mathrm{Cr}$, creatinine; $\mathrm{Na}$, sodium; $\mathrm{K}$, potassium; $\mathrm{Cl}$, chlorine; $\mathrm{Ca}$, calcium; $\mathrm{CRP}, \mathrm{C}$-reactive protein

\section{Declarations}

- Ethics approval and consent to participate: This study was approved by the Institutional Review Board of the Medical Department of the Yokohama City University on April 1, 2019 (approval no. B190200026). All participants provided formal written informed consent prior to study participation.

- Consent for publication: Not applicable

- Availability of data and materials: The datasets generated and/or analyzed during the current study are not publicly available to protect patient privacy.

- Competing interests: The authors declare that they have no competing interests.

- Funding: Not applicable

- Authors' contributions: All authors read and approved the final manuscript and meet the journal's criteria of authorship. MK, MD, KK and YK: Design. MK: data collection. MK, MD, KK and YK: analysis. MK, MD, KK and YK: manuscript preparation. 
- Acknowledgements: Not applicable

\section{References}

1. Michaud L, Büla C, Berney A, Camus V, Voellinger R, Stiefel F, et al. Delirium Guidelines Development Group. Delirium: guidelines for general hospitals. J Psychosom Res. 2007;62:371-83.

2. Inouye SK, Westendorp RG, Saczynski JS, Kimchi EY, Cleinman AA. Delirium in elderly peopleauthors'reply. Lancet. 2014;383:2045.

3. Saxena S, Lawley D. Delirium in the elderly: a clinical review. Postgrad Med J. 2009;85:405-13.

4. Martins S, Fernandes L. Delirium in elderly people: a review. Front Neurol. 2012;3:101.

5. Marcantonio ER, Kiely DK, Simon SE, John Orav E, Jones RN, Murphy KM, et al. Outcomes of older people admitted to postacute facilities with delirium. J Am Geriatr Soc. 2005;53:963-9.

6. Shim J, DePalma G, Sands LP, Leung JM. Prognostic Significance of Postoperative Subsyndromal Delirium. Psychosomatics. 2015;56:644-51.

7. Ouimet S, Riker R, Bergeron N, Cossette M, Kavanagh B, Skrobik Y, et al. Subsyndromal delirium in the ICU: evidence for a disease spectrum. Intensive Care Med. 2007;33:1007-13.

8. Brummel NE, Boehm LM, Girard TD, Pandharipande PP, Jackson JC, Hughes CG, et al. Subsyndromal delirium and institutionalization among patients with critical illness. Am J Crit Care. 2017;26:44755 .

9. Tan MC, Felde A, Kuskowski M, Ward H, Kelly RF, Adabag AS,et al. Incidence and predictors of postcardiotomy delirium. Am J Geriatr Psychiatry. 2008;16:575-83.

10. Breu A, Stransky M, Metterlein T, Werner T, Trabold B. Subsyndromal delirium after cardiac surgery. Scand Cardiovasc J. 2015;49:207-12.

11. Li HC, Chen YS, Chiu MJ, Fu MC, Huang GH, Chen CC. Delirium, subsyndromal delirium, and cognitive changes in individuals undergoing elective coronary artery bypass graft surgery. $\mathrm{J}$ Cardiovasc Nurs. 2015;30:340-5.

12. International Classification of Functioning. Disability and Health: final draft, full version https://www.sustainable-design.ie/arch/ICIDH-2Final.pdf. Accessed 6 July, 2020.

13. Velilla NM, Bouzon CA, Contin KC, Beroiz BI, Herrero AC, Renedo JA. Different functional outcomes in patients with delirium and subsyndromal delirium one month after hospital discharge. Dement Geriatr Cogn Disord. 2012;34:332-6.

14. Wu Y, Shi Z, Wang M, Zhu Y, Li C, Li G, et al. Different MMSE score is associated with postoperative delirium in young-old and old-old adults. PLoS One. 2015;10:e0139879.

15. Van Grootven B, Detroyer E, Devriendt E, Sermon A, Deschodt M, Flamaing J, et al. Is preoperative state anxiety a risk factor for postoperative delirium among elderly hip fracture patients? Geriatr Gerontol Int. 2016;16:948-55.

16. Denny DL, Lindseth G. Preoperative risk factors for subsyndromal delirium in older adults who undergo joint replacement surgery. Orthop Nurs. 2017;36:402-11. 
17. Denny DL, Lindseth GN. Pain, opioid intake, and delirium symptoms in adults following joint replacement surgery. West J Nurs Res. 2020;42:165-76.

18. Peduzzi P, Concato J, Kemper E, Holford TR, Feinstein AR. A simulation study of the number of events per variable in logistic regression analysis. J Clin Epidemiol. 1996;49:1373-9.

19. American Psychiatric Association. Task Force on Nomenclature and Statistics APACoNaS. Diagnostic and statistical manual of mental disorders. 3rd ed. Washington, DC: American Psychiatric Association; 1980.

20. Hattori H, Kamiya J, Shimada H, Akiyama H, Yasui A, Kuroiwa K, et al. Assessment of the risk of postoperative delirium in elderly patients using E-PASS and the NEECHAM Confusion Scale. Int $\mathrm{J}$ Geriatr Psychiatry. 2009;24:1304-10.

21. The Short Confusion Assessment Method (Short CAM). Training Manual and Coding Guide http://www.hospitalelderlifeprogram.org/uploads/disclaimers/Short_CAM_Training_Manual_8-2914.pdf. Accessed 4 September, 2018.

22. Lemiengre J, Nelis T, Joosten E, Braes T, Foreman M, Gastmans C,et al. Detection of delirium by bedside nurses using the confusion assessment method. J Am Geriatr Soc. 2006;54:685-9.

23. Inouye SK, van Dyck CH, Alessi CA, Balkin S, Siegal AP, Horwitz RI. Clarifying confusion: the confusion assessment method: A new method for detection of delirium. Ann Intern Med. 1990;113:941-8.

24. Diwell RA, Davis DH, Vickerstaff V, Sampson EL. Key components of the delirium syndrome and mortality: greater impact of acute change and disorganised thinking in a prospective cohort study. BMC Geriatr. 2018;18:24.

25. Grover S, Kate N. Assessment scales for delirium: A review. World J Psychiatry. 2012;2:58-70.

26. Watanabe A. The Confusion Assessment Method: Validation of Japanese-Language version. Japanese Journal of General Hospital Psychiatry. 2013;25:165-70. [in Japanese].

27. Charlson ME, Pompei P, Ales KL, MacKenzie CR. A new method of classifying prognostic comorbidity in longitudinal studies: development and validation. J Clin Epidemiol. 1987;40:373-83.

28. Mahoney Fl, Barthel DW. Functional evaluation: The Barthel Index. Md State Med J. 1965;14:61-5.

29. Toba K. The guideline for comprehensive geriatric assessment. Japanese Journal of Geriatrics. 2005;42:177-80. [in Japanese].

30. Zeng G, Zeng E. On the relationship between multicollinearity and separation in logistic regression. Communications in Statistics - Simulation and Computation 2019;1-9.

31. Marcantonio E, Ta T, Duthie E, Resnick NM. Delirium severity and psychomotor types: their relationship with outcomes after hip fracture repair. J Am Geriatr Soc. 2002;50:850-7.

32. Maekawa Y, Sugimoto K, Yamasaki M, Takeya Y, Yamamoto K, Ohishi M, et al. Comprehensive Geriatric Assessment is a useful predictive tool for postoperative delirium after gastrointestinal surgery in old-old adults. Geriatr Gerontol Int. 2016;16:1036-42. 
33. Yamamoto M, Yamasaki M, Sugimoto K, Maekawa Y, Miyazaki Y, Makino T, et al. Risk evaluation of postoperative delirium using Comprehensive Geriatric Assessment in elderly patients with esophageal cancer. World J Surg. 2016;40:2705-12.

34. Inouye SK, Westendorp RG, Saczynski JS, Kimchi EY, Cleinman AA. Delirium in elderly people. Lancet. 2014;383:2045.

35. Strategies to end seclusion and restraint. WHO QualityRights Specialized training: course slides https://apps.who.int/iris/handle/10665/329747. Accessed 23 June, 2020.

36. Chen H, Jiang H, Chen B, Fan L, Shi W, Jin Y, et al. The Incidence and Predictors of Postoperative Delirium After Brain Tumor Resection in Adults: A Cross-Sectional Survey. World Neurosurg. 2020. doi:10.1016/j.wneu.2020.04.195.

37. Yamada C, Iwawaki Y, Harada K, Fukui M, Morimoto M, Yamanaka R. Frequency and risk factors for subsyndromal delirium in an intensive care unit. Intensive Crit Care Nurs. 2018;47:15-22.

38. Liu X, Yu Y, Zhu S. Inflammatory markers in postoperative delirium (POD) and cognitive dysfunction (POCD): A meta-analysis of observational studies. PLoS One. 2018;13:e0195659.

\section{Figures}

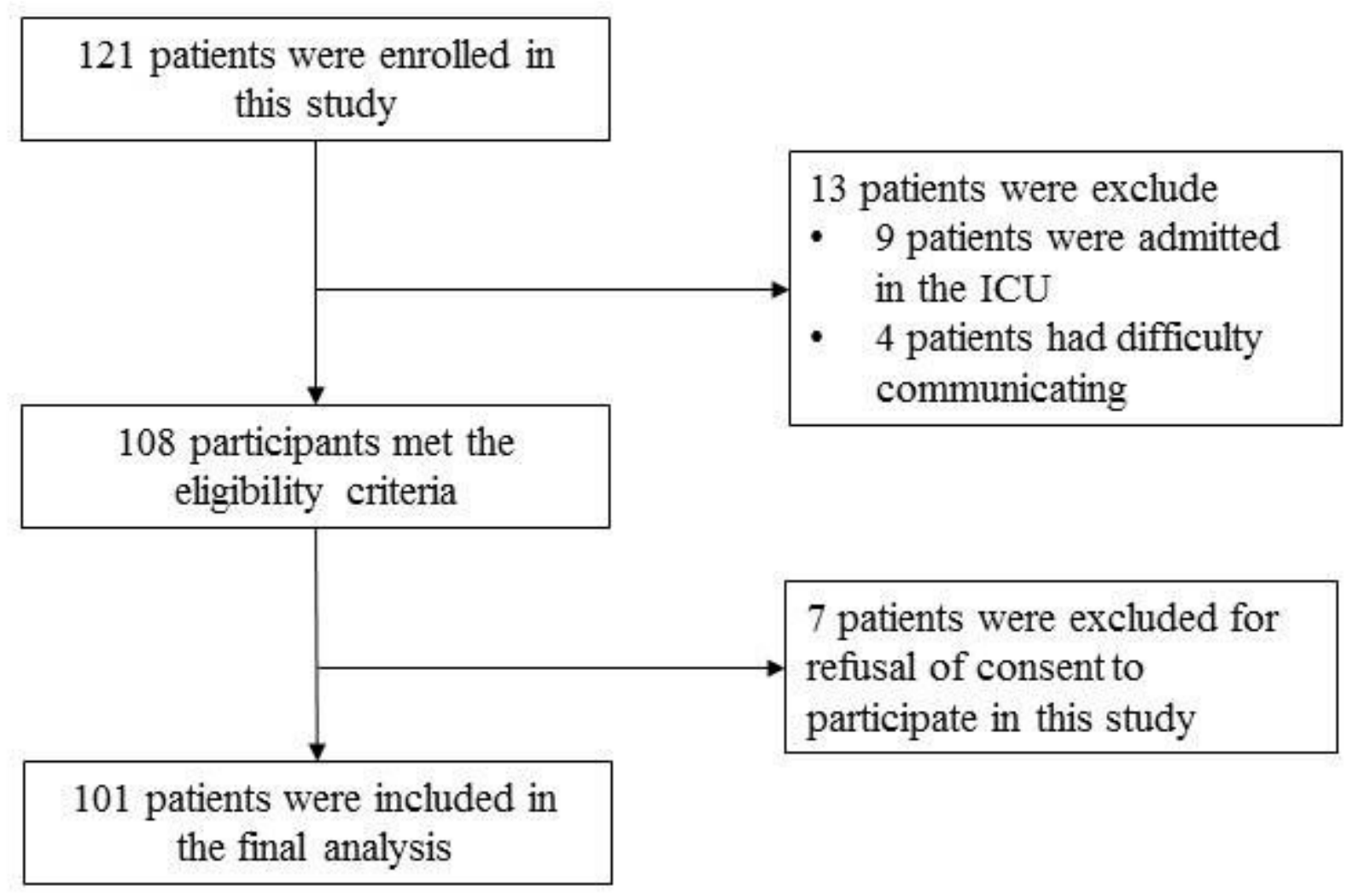


Patient enrollment flowchart

Page $17 / 17$ 